\title{
Social dimensions of distance postgraduate education in Greece
}

\author{
Karaoulanis Andreas MBA MScEng \\ andrekaraoul@gmail.com
}

\section{ABSTRACT}

Although distance learning has no less effectiveness than on campus education (Young J, 2000), is still unclear why Greek students adopt the HOU for their postgraduate studies. This research addresses the following questions: "What makes the Greek students to decide to pursue their postgraduate degree via the HOU instead of the on campus one? Which are the factors affecting their decision? Which are the most important of them?"

This research followed the survey methodology with the use of email questionnaires which followed the snow ball technique, while the results were analysed by the Dedoose software.

The findings indicated that reasons like financial needs, time, flexibility and job prospects are influencing students towards their decision, while factors like family and friends are the catalysts in that direction.

Our analysis suggests that the results can help HOU understand that need to help students overcome their contemporary societal barriers towards a better future.

\section{Indexing terms/Keywords}

distance learning, education, HOU, social, postgraduate

\section{Academic Discipline And Sub-Disciplines}

\author{
Education
}

\section{SUBJECT CLASSIFICATION}

Human- Computer interaction

\section{TYPE (METHOD/APPROACH)}

Survey

\section{INTRODUCTION}

\subsection{Background}

Distance learning education has been used the last years to deliver remote site or off- campus courses in a variety of fields, like business, teacher education, medicine and nursing etc. (Burges, 1994, cited in Collins et al., 2003).

According to E.K.E.P ${ }^{1}$ (n.d.), people nowadays facing environments of increasing demands and speed in terms of information flow, something which creates the need for continuous re- education and re- training.

In the so demanding times we are living, an increasing number of students take advantage of the distance education. It is amazing that according to the HOU's (Hellenic Open University's) data base, the application for postgraduate studies in 2000 were 10,317, while the same applications for 2015 were 25,618 (Hellenic Open University, n.d.), an almost 40\% increase the last fifteen years.

It is very important to understand not only why students choose this kind of education but also if the institutes that offering it are fulfilling their obligations in an adequate way (Guthrie, et al, 2010). In terms of the HOE, under the influences of the European education policy, an emphasis is placed in Greek policies about the issues of the studies' accreditation and quality assurance (Prokou, 2014). Emphasis also is placed to the formation of the qualifications framework, in order to incorporate the distance learning students' vocational status with the existent vocational framework in the country (Prokou, 2014).

According to Patiniotis (2015), people who decide to apply to the HOU are people who want to re- invent themselves and to approach society from a different perspective. They want to be transformed and they see this opportunity as their big chance as they are in their majority people from socially excluded groups.

The social presence in an online distance learning platform, a paragon which can be important in terms of expressing the students' profile, can be depicted by five facets, which are, the social respect (i.e. receiving timely responses), social sharing (i.e. sharing information or expressing beliefs), open mind (i.e. expressing agreement or receiving positive feedback), social identity (i.e. be called by name), intimacy (i.e. sharing personal experiences) (Sung et al., 2012).

The online distance learning can take place via three different modes, namely, synchronously, asynchronously, or a combination of both (Friday, Friday-Stroud, Green, \& Hill, 2006, cited in Perkowski, 2012). Synchronous communication takes place in "real time", while asynchronous occurs, mainly, via discussion boards within a virtual environment or via e

\footnotetext{
${ }^{1}$ National Centre for Vocational Orientation
} 
mails. The combination of both of them gives us the third distance learning mode which is a blend of the first two (Perkowski, 2012).

Reese (2015), indicates that a balanced online educational environment should be able to provide a blend of both synchronous and asynchronous opportunities, in order to promote collaboration and communication among classmates and instructors. This is a very important paragon which can affect the quality of the education in question as a determinant in decision making of which path, between the two provided, one should follow.

The differences between the distance learning courses and the on campus ones are mainly the following:
$\checkmark \quad$ Learning in classroom
$\checkmark \quad$ Face to face time with professors and teachers
$\checkmark$ Campus atmosphere
$\checkmark \quad$ Student activities, thus social linkage
$\checkmark \quad$ Camp based help centres (distancelearningschools.org, n.d.).

Another important paragon which differentiates these two forms of studying is the flexibility distance learning courses can provide (distancelearningschools.org, n.d.).

Although there is a great deal of evidence indicating that there is no significant differences to be expected regarding the effectiveness between on line and on campus education (Young J.R., 2000), significant differences still exist in the way students perceive their online experiences (Muilenburg, et al.,. 2005).

This research addressed the problem of the lack of knowledge about the factors which affect the adoption of distance learning education on postgraduate level, in contemporary Greece instead of the traditional on campus one. There are a lot of studies which have addressed the challenge of online education (Sabine et al., 2012; Malataras et al., 2007; White et al, 1999; Gravani et al., 2012, Smith, 2010, Gemmell, et al., 2015 etc.), however, it is still unclear which are the main factors affecting the Greek students' decision to follow distance learning studies instead of the on campus ones.

In spite of the fact that hundreds of studies till now have addressed the issue whether remote instruction is as effective as traditional face to face instruction offered on campus (Collins et al., 2003), the question why students decide to follow the path of the remote instead of the on campus one is not studied adequately enough yet.

The research problem can be described from the above as "the lack of knowledge in terms of which factors affect the adoption of the distance learning postgraduate education in contemporary Greece". The significance of the problem is very high because a large number of Greek families in contemporary Greece are living under or near poverty, they find it very difficult to afford the money needed in order to support their children's education. Also, there are other societal factors which create difficulties in overcoming potential incumbents posed by society to the Greek citizens in terms of pursuing a reliable and of high standards postgraduate education. According to Vergidis et al. (2002), open universities are here to serve people's needs for education by overcoming socio- economic barriers and offer education to sensitive population groups like unemployed, handicapped, mothers, emigrants, immigrants etc. The significance of distance learning on societal level is underlined by Patiniotis (2015) who indicates that it is time for the Greek society to start the conversation about the distance learning education and how it can be conveyed to the traditional forms of education as its proclivity is enormous.

The problem has a vast scientific importance as it can help the teaching stuff of the HOU to better understand the needs and the paragons which drive its students to attend such courses. This understanding will help HOU to address better policies in terms of i.e. meetings needed, exams, and assignments and of course fees. Also, it can be food for thinking for Greek scientists who are responsible for such courses, as it can give them a valuable feedback from students who chose this kind of study in order to be better in terms of scientific approach to several matters like how to deliver a lesson which is addressed to professionals in a concise thus time sensitive manner but efficient too. . Understanding the role of the learner's sense of presence may be very important for the tutors in such distance learning situations, as the learner and the tutor are physically separated (Sung et al., 2012).

Finally, this study can be helpful to the Greek state too, which need to understand that due to the ongoing crisis, priorities in terms of business and education have changes the last years for Greeks, who strive to find a better future sometimes via an affordable, flexible educational path.

\subsection{Aims and Objectives}

2. The aim of this research is to describe which factors affect the Greeks students' decision, to pursue their postgraduate degree via the Hellenic Open University online educational platform instead of the traditional one of the on campus education.

3. The objectives of this research were the following:

4. To distinguish the different tendencies/ factors that affected the respondents' decision to follow the HOU's distance learning path. 
5. To rank the factors in question in a qualitative way according to the students' answers in the questionnaires that were provided. In that way, the importance of each factor was highlighted.

\subsection{Research questions}

The research questions this study addressed are the following:

"What are the factors that affect the Greek students' decision to pursue their postgraduate degree via the Hellenic Open University instead of the traditional, on campus one? Which are the most important of these factors in affecting the students' decision?"

\subsection{Limitations of the study}

This research, has the following limitations. The most important of which are the following:

4 The respondents that selected were convenient, which means that they were people easily reachable, something which created a bigger bias than if the sample was i.e. systematic (Queensland Health, 2007). Also, factors like age, gender or socioeconomic situation were not asked, something which also created some bias in the results as it constrained the outcome in a way.

4 The study restrained in a specific area as it examined the responses of students in a specific course in a specific location (Thessaloniki and neighbouring counties), which means that we had the bias of a non- national wide sample.

4 Restrictions posed by the DSV department in terms of not involving with any official capacity of any company or organisation for this research, as well as time limitations as this research was made in the boundaries of the FMVEK module under the DSV department of the Stockholm university, created additional bias.

+ The size of the sample could not be big due to all the above mentioned restrictions, something which accordingly created a bias as well.

\section{METHODOLOGY}

According to Yin, there are numerous ways to carry out any kind of research i.e. experiments, surveys, archival analysis, history and case study methods. Their selection depends on three conditions (2014, p.9), the type of the research questions, the extent of the control a researcher has over actual events which usually are behavioural ones, the degree of focus on contemporary events.

In this research a survey methodology was used in order to bring the best possible qualitative results. It aimed to provide a snapshot of how things were at a specific point of time and tried to bring things up to date (Denscombe, 2010, p.12) in terms of students' decision to follow the specific kind of studying (online).

According to Denscombe (2010, p. 13), internet surveys can take the form of a questionnaire sent as an attachment to an email. In this research, questionnaires is the method that was followed in terms of data collection, as it will be explained in the paragraphs to follow.

\subsection{Data collection methods}

The information needed for answering the research questions mentioned in chapter 1.5, is information about the student's behaviour in terms of why they choose the distance learning approach. Also, information about the factors affecting this kind of decision and finally, information about the importance of these factors.

The data collection methods that can be used for social research like this one are, according to Densombe (2010, p.4), things like questionnaires, interviews, observations and documents. Such methods although are appropriate for this kind of research, in the specific case of the HOU and according to the limitations posed from the DSV department in terms of not to doing any research projects with organizations or stakeholders involved in any official capacity. From the above mentioned methods, this research used the questionnaires one. The reasons for choosing this method are because questionnaires is a method which is very positively aligned with the aims of this research, as they can bring the feedback needed from the students which needed in order to understand their decision motives. Also, they were a great asset to the research in both classifying the students in terms of their motives in decision making as well as in ranking the factors which affected their decision in terms of their importance. Finally, the questionnaire method of data gathering was well aligned to the very problem of the lack of knowledge in why Greek students follow the HOU approach as they eventually answered this question providing the students' answers.

Another reason is because the information given by questionnaires is mainly "facts" and "opinions" which, especially the second, is exactly the aim of this research (Denscombe, 2010, p.156).

Also, they served this research better than i.e. interviews as it is very difficult and time consuming to interview people from different cities with different vocational backgrounds thus time schedules.

Finally, another important reason is because in terms of comparing questionnaires with other forms of data gathering methods like observation and/or documents, the questionnaires method seemed to be the most suitable one, as it provided the researcher with straight answers from the people involved to the situation thus bias is much less. Also, it didn't involve the researcher's personal opinion or bias. 
This research made use of the internet questionnaires and especially e- mail questionnaires (Denscombe, 2010, p.159). This option was chosen instead of "questionnaires sent as an attachment to an email" or "web- based questionnaires" (Denscombe, 2010, p.159), only because they are very easy to be respondent, something which created a positive attitude to the respondents in answering them. Of course such questionnaires did not have the same output like the attached questionnaires or the attractiveness of the web- based ones, but with the reachability problems and the time limitations that existed, the email questionnaires solution seemed to be the best fitted for this research.

Questionnaires can have some important disadvantages like that they offer little opportunity for the researcher to find out if the answers given from the respondents are truth (Densombe, 2010, p.170), or that when they use pre- coded questions they can probably create bias towards the researcher (Denscombe, 2010, p. 170) as in some terms the respondent is guided and restricted in specific answers. In such occasions pre-coded questions can be frustrating for respondents thus deter them from answering them (Denscombe, 2010, p.170)

On the other hand, questionnaires have many important advantages which were the reason for choosing them in the first place and which are the fact that they are economical, as this research used email questionnaires. Also, it is relatively easy to arrange them, and they provide standardise questions to all respondents thus driving them to standardised answers. Another important advantage they have is that they can use pre-coded questions which although can create some problems, as we saw in the disadvantages part, they can also give some strong advantages like the speedy use of the results given in terms of analysis (Denscombe, 2010, p.169).

In this research only open ended questions were used as the research had a qualitative scope. A combination of both qualitative and quantitative approach, although it would probably generate more in depth results, was out of the scope of this project due to time and size limitations posed by the DSV department.

Questionnaires are very well used in social science research for acquiring information on participant social characteristics, present and past behaviour, standards of behaviour or attitudes and their beliefs and reasons for a specific action with respect to the topic in question (Bulmer, 2004, cited in Bird, 2009, p. 1307).

\subsection{Data Collection Strategy}

The sampling technique that was used in this research project is the snowball sampling (Denscombe, 2010, p.37), which is also known as cold-calling, chain sampling, chain-referral sampling, and referral sampling (statisticshowto.com, n.d.), because is a technique which provides to the researcher the distinctive advantage of being nominated from one respondent to another, something which creates credibility and increases the possibilities for the potential respondent to feel safe enough to reply to the questionnaire provided (Densombe, 2010, p.37).

This kind of sampling technique is very well suited to small scale exploratory samples and in conjunction with qualitative research (Denscombe, 2010, p.37), which is exactly the case with this specific research's aim. The snowball technique gives to the researcher the advantage not to pick the respondents by himself thus to eliminate possible bias in the picking process, while it creates other biases like that the sample is not representative or that the respondents had the same characteristics as they probably are part of the same social group with the ones that nominated them. Also, it is possible that the one respondent could be able to influence the other as they could be familiar with each other.

This technique has an important bias which is that is almost impossible for the researcher to determine the sampling error or to make inferences about populations based on the obtained sample (statisticshowto.com, n.d.), something which implies that a bigger scale investigation of the problem could help future researchers more.

The sample size was expected to be somewhere between 20 and 25 participants. Such sample was chosen to be the best minimum that was suited to this research because there is a general tendency to choose the minimum sample size which is feasible depending on the resources (time and budget) (Denscombe, 2010, p.47). Due to the time limitations of this study, a larger sample would have been time consuming. This research didn't use interviews mainly because the interviews approach needed a lot of time and maybe travelling, as many of the respondents lived in different cities, something which was not feasible due to the time restrictions of the study and the budget restrictions of the researcher. Also, is not sure that a bigger sample would have been really assisting in developing better outcomes for such a small scale research due to the possible saturation. Another issue was that this project needed a lot more time in terms of qualitative analysis of a much bigger data sample would have been chosen.

The time needed for the data collection under this technique is estimated to be about 10 days, something which is very convenient for a short scale research like this one.

In terms of data saturation, as the study was a qualitative one as described in previous paragraphs, the researcher valued his data findings in terms of in what degree they repeated themselves during the data gathering. Although data saturation is a quite controversial issue (O' Reilly, et al., 2013), it is very important to reach saturation in terms that this phenomenon will establish a well- grounded qualitative result.

On the other hand, reaching saturation is an important indicator for the researcher in order to help him understand that he can stop there and not to go on with the process as a satisfactory result has reached. So, in terms of time consume this was very important. In this research, data saturation was achieved by the researcher when he understood that more than $70 \%$ of the respondents gave the same answer to the same topic. Although this was an arbitrary decision from the researcher, there were no explicit guidelines on how or when saturation could have been achieved (Bowen G.A., 2008), so the researcher also used his experience on this matter. In this specific research, where the sample, thus the responses, was quite small due to limitations posed from the beginning, the saturation point was reached only in one occasion, which was the answer to the question "Why did you choose distance learning only at postgraduate level and not for your 
bachelor's degree?" where the big majority of the respondents said that when they were younger they didn't have that option. So, the arbitrary posed $70 \%$ of data saturation was not crucial for this study or was involved in the results in any way.

Also, exploratory data samples were very well suited for such small scale studies as each respondent from this small generally sample, was being studied in depth and more detail (Densombe, 2010, p.41) and the sample only needed to be sufficient in size in order to enable the researcher to feel that enough information has been collected (Denscombe, 2010, p.41).

\subsection{Data Analysis}

According to Denscombe (2010, p. 235), analysis is something we do in order to gain a better understanding of things through a detail examination of the subject in question. In this part, the data analysis of this project was examined on the basis of qualitative analysis via the email attached questionnaires as was described in previous chapters. The analysis followed the inductive path as the researcher strived to work from the particular to the general (Denscombe, 2010, p.273). In that way, the researcher tried to gather the individuals' answers and convey them into a bigger frame in order to reach to the generalization needed for categorizing the data gathered. The whole process of the analysis used the Dedoose software by which the researcher did the coding, i.e. self- discipline, social networking etc. and connected the responses to the specific codes in order to generalize the results.

The qualitative data analysis is predominately concerned with the analysis of talk and text (Denscombe, 2010, p.279). The data analysis also followed the pattern provided by Denscombe $(2010$, p.240), according to which, there was a data coding, a grouping of the codes assigned to the data into specific categories or themes, a comparison between the different categories and finally an investigation about hidden concepts or other abstract categories inside the texts.

According to Denscombe (2010, pp. 284-287) the data coding followed some key stages like codes categorizing, reduction of number of codes and categories, hierarchy development of both codes and categories and finally the check of the emerging codes, categories and concepts with the data, move towards key concepts. The data was divided according to the above mentioned plan in several categories which followed different potential streams of how the respondents answered to the questions provided. In chapter 3.1., a more analytical description of the data analysis is presented.

\subsection{Research ethics}

Denscombe (2010, p.331) stresses that social researchers need to protect the interests of the participants, to ensure via the informed consent form, that the participation is voluntarily, that the research avoided deception based on scientific integrity and that the research was complied to the laws of the land (Greece).

This research did not yield any risks to participants in any way. Their anonymity was priority number one for the researcher, as the emails that were received were permanently deleted after the data gathering. Also, no confidential questions were asked in terms of sensitive information about the respondents. The researcher did not gather any information about their gender, marital status, name, address or occupation or anything else that would have been hazardous for them, or would prevent them from participating by feeling uncomfortable in any terms.

The data was stored in three different ways, namely, in the hard drive of the researcher's desktop computer, in an external hard disk and also were printed in order to be kept in a hard copy too.

\section{RESULTS}

\subsection{Data Collection and Analysis}

According to Dencombe (2010, p.240), the data preparation plan for the qualitative analysis includes the cataloguing of the text or the visual data that was gathered, the preparation of the data and its loading onto the software that was be used and finally, the transcribing of the available text.

The data was gathered via questionnaires which were email attachments. The whole procedure for the data gathering last about ten days. First the questionnaires were constructed in a way to help the researcher to get answers to his research questions. As the snow ball technique was used, the first eight questionnaires were sent to respondents who were, in a way, researcher's acquaintances. This technique allowed finally, the gathering of twenty two responses via email.

All of the eight participants who were approached in the first place in order to start the snow ball effect, respondent, something which made easier the collection of the responses. The whole procedure started on Sunday the fourth of December 2016 and was concluded on Tuesday the $13^{\text {th }}$ of December 2016.

Each questionnaire was indexed by a serial number in terms of the first eight questionnaires so every questionnaire that was received afterwards as result of the snowball method, was indexed with a letter accordingly. For example, if the respondent number 1 have sent back 2 more questionnaires, these took the number $1 \mathrm{a}$ and $1 \mathrm{~b}$, so the researcher was able to follow the line of each questionnaire in order to be able to recognize any potential bias.

One thing that was a priority it was the researcher to translate into English some of the responses, as some respondents replied in Greek.

The data was prepared as the researcher categorized the responses to specific categories depending on what the answers of the respondents were. For example, if some respondents replied that they followed distance learning due to 
financial reasons, financial reasons was one category. If some others responded that they followed this kind of education due to time restrictions, time was another category and so on.

After the data was categorized, was loaded onto the Dedoose software in order to get the qualitative results needed.In figures 1 and 2 we can see the codes selected by the researcher in a 3-d presentation as was screenshot via Dedoose (figure 1), while we can also see the factors that affected the respondents' decision to follow HOU in connection with the questionnaires as coded by the researcher (figure 2).

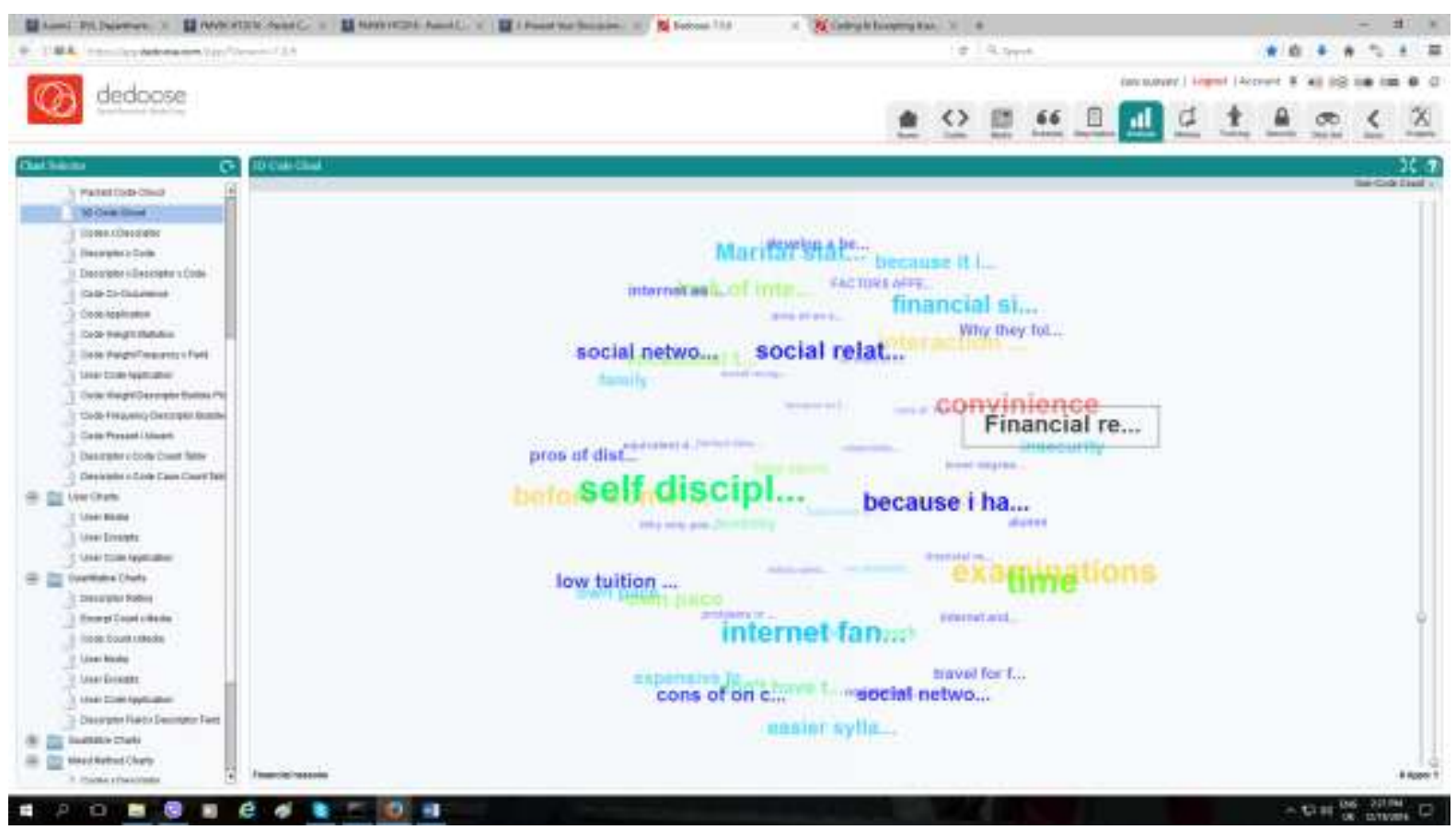

Figure 1: Dedoose screenshot: Presentation of the codes

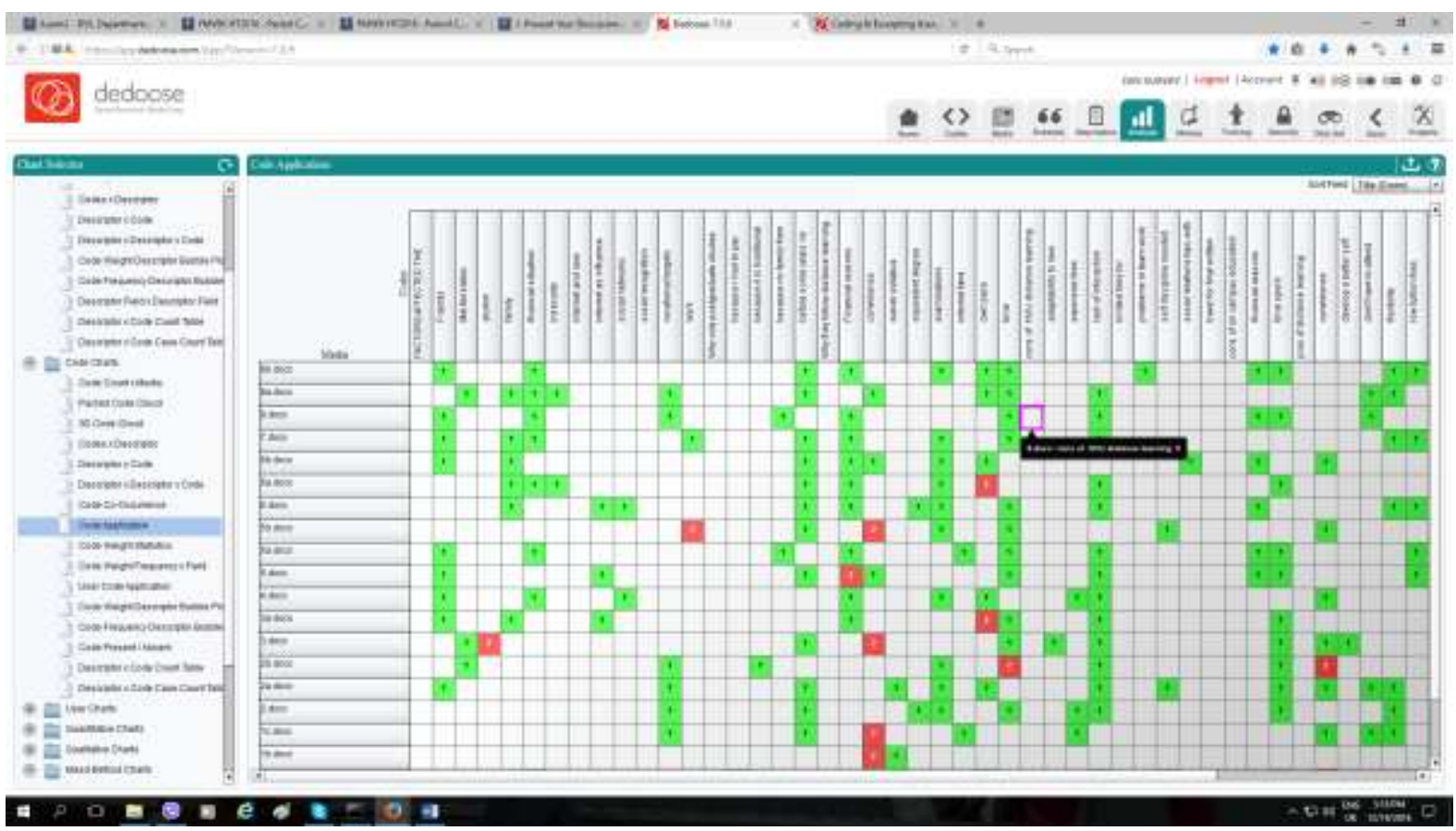

Figure 2: Dedoose screenshot: Factors affected respondents' decision

The first thing while using Dedoose, was the codes creation. Five codes created, one for each one of the questionnaire's questions. Also some sub codes created in order to help the researcher to categorise the different responses to each question. For example, the question "why you chose to follow distance courses? Give us 3 to 5 reasons. Write them with significance order" was the first code, while some sub codes for it were the time, financial reasons etc. Every sub code was given a priority number in a scale from 1 to five for the five reasons that the majority of the respondents was asked to present in their answers. The researcher created descriptors and linked them to his data after he uploaded the research questionnaires onto the software. The analysis was achieved by connecting the separate data elements.

\section{7 | P a g e}

J a n u a y, 2017 


\subsection{Results}

Several trends were discovered under this question. The majority of the respondents were facing three main reasons which were the major incentives for them in order to choose this kind of education. These reasons were the time, in terms that the distance learning courses can gain you valuable time to spend to your job, family, friends or yourself, the fact that you can give to your studies your own pace, something which is obviously connected with the time as well and the financial factor which, especially nowadays in a Greece which is under a vast financial crisis is an important one. Responses like "there is great flexibility when it comes to correspond with the university's demands" or "being able to complete the different assignments when and where I want" or "don't have to spend much money, is 650 euros per module" are indicative of the above mentioned trends

Of course there were other several trends that were depicted though the data analysis, like that everybody were accepted thru an elective procedure, so by complete chance and no form of exercises needed and the work- studies balance, which according to the researcher's opinion is also correlated to time. Such trends are depicted in several quotations too like the following, "it didn't require any examinations to get into the university; you were being picked by random" or "saving time (able to fit studies and work)".

Finally, other minor trends were detected, like the "love" of internet and new technologies, the recognition that an online degree has from the Greek state, the perception of some that online lessons are easier, the fact that students can choose between lessons which are not available on campus, the fact that no written exams needed, that subjects studied are very interesting, and that many students have a family to run in parallel with their studies. Quotations that used were like the following, "I found the subjects very interesting", "it is convenient when you have familial obligations and limited timeframe", "I love internet and new technologies", "the degree in distance postgraduate has the same recognition as in on campus". The above mentioned quotations describe these minor trends which are indicative of what the students had in mind while deciding to follow this kind of studies.

It is important here to notice that in terms of significance order, the response that was the first priority for the majority of the students was the financial paragon while the time paragon was the second more popular.

\subsubsection{Factors affecting students' decision}

In terms of data gathered as response to the question "which factors affected your decision?" the respondents' answers were mainly focused on friends and family as the main influential factors for their decision making. The big majority of the respondents answered that their family was the most crucial paragon in affecting their decision. By the term family, they meant their parents and brothers but mainly their partners, who strongly influenced their decision by pushing them towards such kind of education. Quotations like "my husband's experience" or "I was influenced by my friends who were attending similar programs" denoted this trend.

Other factors were the financial situation of the individual, the job prospects relating to a post graduate degree, the social environment which creates insecurity, thus the need for evolvement thru i.e. a post graduate degree, the opinion of alumni, the internet advertisement and the social networks like Facebook and Linked in. All these trends were underlined by quotes like "it was imperative for me to have a post graduate degree due to my social insecurity", "the limited time due to the nature of my work and my family obligations.", "because I had to study as I was insecure but I didn't have the time or the money to go to an on campus university", or "the need of having a master in our society" etc.

From the significance order the respondents responded about the factors affecting their decision, the results were demonstrating that the most important factor was their family, while the next one was their friends, while the third one was the insecurity they were feeling due to the socio- economic environment in contemporary Greece. Other less important factors were alumni, internet ads and social media.

\subsubsection{Comparison between the distance and the on campus education}

The research's questionnaire continued with three more questions which all were asking about the pros and cons of the two types and in addition why students tried the distance learning type only in post graduate level. Such questions were made in order to give a clearer picture of the two first questions which also tried to answer the research questions. So, these questions were posed in order to dig deeper into the first two.

The responses were divided in two sections, the one which included the pros and cons of the distance type and the ones which contained the pros and cons of the on campus one. Finally, we had the answer to the question why to choose distance education only on post graduate level.

In terms of distance education, the pros that the respondents indicated were flexibility, time, own pace, self- development in terms of discipline, organization of the materials, the reduced fees, no compulsory meetings, the lessons seem easier than on campus. Something which got the researcher's attention was one response which was in the opposite direction as a respondent argued that distance is not a con but a pros. This response was in contradiction to all the others. Also, there was a response which indicated that the limited meetings are a pros and not a con. That was in contradiction too with others, as the majority underlined that distance is a con in terms of contact with the teachers and the fellow students. Some quotations that are indicative of the above mentioned results are "pros: time, flexibility, limited meetings, lack of interaction", "flexibility on the hours you have to work", or "there are no compulsory meetings and lessons" and "..right from the start of the subject, there was very precise organization of the material of the subject. You have also given headup about your obligations" etc. 
On the antipode, the cons that were registered were the need of use of technological tools, large volume of studying, comprehension problems, difficult to reach professors for questions, lack of social interaction with professors and costudents, the own pace can mislead to wrong estimation of time, there is not always the right guidance in terms of studying, difficulties of cooperation when team work needed, the fees. In general, the main trend was the lack of face to face communications in terms of the bipolar teacher- student as well as the student- student one. Also, one major con that was unveiled was the problem that students cannot ask questions on spot while they studying and facing a specific problem in terms of comprehension. Some quotations that justify the trends mentioned above are "hard to communicate with professors via emails", "you cannot ask questions on spot to solve any problems that might arise", "there is not always a specific guidance in terms of studying from the professors" etc.

In terms of the on campus pros, the main trends were the face to face meetings, the precise guidance, resolving questions on the spot, daily feedback from tutors, does not require special knowledge and skills, familiarity, social networking, more focused during classroom lessons. On the other hand the cons that sprung were, time, working and studying impossible, money needed, no flexibility, lack of projects, obligatory participation and you have to participate to exams in order to get admitted. Some quotations that describe the above mentioned are the following: "the pros are that you are there physically, while the cons are that you have to travel or relocate or spend time and money", "you participate to the lessons and listen to the lectures. Also, you interact with your fellow students and professors", "classes last many hours, so you spend a lot of time on campus" etc.

The majority of the pros and the cons had to do with the physical presence and all its consequences and the money. The respondents in their smashing majority said that time and money are the major cons, while physical interaction is the major pros. Physical interaction results in better social networking, resolving questions on the spot and get daily feedback from the tutors, something which means that the majority of the pros described above are correlated under the label of physical interaction/presence.

Finally, the respondents had to answer why they chose the distance education at HOU only for their postgraduate studies. Here the results were as follows. Many respondents replied that when they pursued their bachelor's degree they didn't have the option of distance learning. Also, we had responses like "distance bachelor programs are only few", "I need my master's for my job so I didn't consider it in the past", "because bachelors are cost free in public universities", "because distance degrees in Greece are considered of lower status", "I was unaware of it while on my early years", "because I had not a family of my own then" etc.. In general, the main stream was that HOU was not there before 15 or 20 years, something which is very important as the big majority of the respondents are over thirty.

\section{DISCUSSION}

\subsection{Main findings}

The results of this research showed that, in terms of the factors that affected this decision, the majority of the Greek students follow the HOU due to financial reasons, due to time limitations they had and due to the fact that they can follow their own pace. Also, other important factor in that direction were family, friends and that HOU gave them the opportunity to pursue a better vocational future.

Finally, the results also showed that the big majority of the respondents did not choose distance education on undergraduate level because when they had to follow their studies such option didn't exist.

\subsubsection{Answers to the research questions}

The answer to the first research question "What are the factors that affect the Greek students' decision to pursue their postgraduate degree via the Hellenic Open University instead of the traditional, on campus one?" was that they pursued their degree via the HOU because they cannot afford the on campus one, because they don't have the time needed to follow the on campus, because they need flexibility and their own pace of study as they had to create a balance between their work, family and studies, and because with the HOU they did not have to give any kind of exams in order to be admitted, something which was very important to them as they could gain time and money for their preparation. Also, factors like the family's influence, friends and financial reasons were other important factors. Finally, factors like internet advertisements, alumni and social media were also some factors but not as strong as the first ones.

The answer to the second research question "which are the most important of these factors in affecting the students' decision?" was that the most important factor was their family, while with term family the big majority of them meant their partners. The next more important was their friends and the third more important was the socio- economic situation in contemporary Greece which increases their insecurity and as a result they tend to pursue a better qualification to secure a better future.

\subsection{Connection between main findings and previous research on the topic}

The research results in their big majority are in accordance with the previous research on the topic.

As presented in the background section of this study, people nowadays facing environments of increasing demands and speed which creates a need for continuous education (E.K.E.P, n.d). This is in accordance with the result which stated that students feel insecure and need to cover that gap with their further post graduate level education. 
As Patiniotis indicated (2015) distance learning helps people to re- invent themselves and approach society from a different perspective. This was underlined by the respondents' trend that they can built a self-discipline approach via the distance learning process.

In terms of differences between distance learning and on campus courses, what we saw in chapter 1 from the distancelearningschools.org (n.d.), is in compliance with the findings of the research. As respondents indicated the main problems with the distance learning are the interaction ones with both classmates and professors while the advantage of the on campus learning is the social linkage and the face to face teaching. The respondents did not stated anything about the campus atmosphere or camp based help centres. (distancelearningschools.org, n.d.).

Another trend that was depicted by the respondents' answers was that students need to overcome social and economic barriers like motherhood, thus family and time needed and money for their studies. This is in complete accordance with what Vergidis et al. (2002) indicted when he stated that "open universities are here to serve peoples' needs for education by overcoming socio-economic barriers and offer education to sensitive population groups like unemployed, handicapped, mothers etc".

The respondents' concern about the lack of face to face (synchronous) teaching was not adequately presented by the literature, thus a minor deviation here can be underlined. The respondents stated that a very big disadvantage of the online education is the lack of interaction between students and their tutor as well as the lack of answering their questions on the spot. According to Friday; Friday-Strout; Green \& Hill (2006, cited in Perkowski, 2012), the combination of synchronous and asynchronous tutoring is one of the three main forms of distance education, while Reese (2015) indicated that the balance of these two methods can promote the collaboration between tutors and students, something which seems from the results that is not happening in $\mathrm{HOU}$, at least not in a big degree.

In general, we can say that the results of the research were in line with the literature and were as expected in their majority. Minor deviations like the response "one pros of the online education is the lack of interaction" cannot alter the general concept.

\subsection{Main findings' importance}

Although the theoretical contribution of the study in terms of why students pursue the HOU degrees in postgraduate level is important, this very study can be the yardstick for future research. The contemporary environment in Greece is quite toxic in terms of financial prospects and barriers to knowledge due to the lack of means and funding. In such environment with unemployment rate of $23.2 \%$ (Siklaridi- Kolasa , 2016), insecurity is easy to increase, while the need for higher education and specialization is prompt and huge. It is also important, although it was not very clear from the responses to the questionnaires, that there is a social "shadow" behind the students' decision to follow distance learning studies. This "shadow" implies mainly two things, that there is a social need for some students to pursue a post graduate degree in order to feel societal accepted in a higher degree, while some students choose this kind of education due to its equivalence to the on campus one. Although the first one wasn't completely obvious from the responses and the researcher had to dig deeper into them, the second one is a vocational must for the Greek society. It is important here to underline that the Greek state is very austere in terms of distance learning education something which results in not recognising the majority of foreign distance learning degrees.

It is obvious from the above that the practical implications of the study are vast as we have to deal with a socioeconomical phenomenon which can alter the whole educational system in Greece and give hope to the poor and the minorities which for some reason can be social excluded.

\subsection{Results' limitations}

This research, as we saw in the limitations part, had several restrictions mainly due to time limitations. An important limitation that might be taken under consideration is the researcher did not get into his consideration any demographics of his respondents, like their gender, financial situation, age etc. In order to eliminate potential bias that would have sprung from such details he wasn't able to eliminate the bias that sprung from the very absence of such details. Another reason for not mentioning such demographics was to decrease the size of the data due to time restrictions, while another reason was in order to achieve a better response rate from the respondents, something which had $100 \%$ as the respondents felt comfortable enough to answer the given questions as no personal information was asked.

Another limitation of the study had to do with the sample size. In order to be achieved a more detailed result, a bigger sample should be gathered. The lack of time created this phenomenon which of course affected, at a degree, the accuracy of the results. Of course, the researcher achieved a high degree of data saturation which means that the increase of the sample in some cases would have not been given a more accurate result, but in some cases that would have been possible.

\subsection{Quality criteria of the research results}

The results of this research are believable. Everything that the respondents indicated with their answers can be easily seen from someone who is living in contemporary Greece. The socioeconomic paragon which is very obvious throughout the results creates several other problems to Greeks nowadays. Also, the researcher tried to triangulate his results in the best possible way. Although there were certain time limitations, the triangulation was achieved by asking several other exstudents of the HOU as well as by discussing informally with classmates and academic acquaintances. Of course, there wasn't sufficient time for a better and deeper triangulation of the findings, something which can be done in a future research with less time constraints. 
The conformability of the study can be achieved by studying the data loaded onto Dedoose, which supported the results of the study as presented by the researcher. All the results presented were extracted from the given data and the connections Dedoose created between different parts of this data. The scope of this research was to bring a new perspective to a well- known subject like the distance learning education and the credibility of this projects will be judged by future readers on the basis of the data gathered and the findings.

The research as described in the previous sections provided a quite high degree of description and methods. Also, although there were certain limitations, as mentioned before, the researcher tried to focus on the specific situation that the topic needed in order to help the potential future reader/ researcher to be able to use this study to other contexts, though the transferability of the study can be derived that was quite high albeit the restrains posed from the beginning.

Finally, the research was presented in a quite big detail in order to assist future researchers to repeat similar researches in larger scales in order to achieve similar results in a bigger scale. The small size of the sample as well as the restrained scale of the research, i.e. was examined only one course of the HOU while there are many more with different population etc., created space for future researcher in terms of analysing deeper the socioeconomic phenomena which were presented in that research. As result of the high degree of analysing the techniques used, the data gathering, the sample etc. the research should have a high degree of dependability.

\subsection{Future research}

Future research could involve the unravelling of the deep social stereotypes in Greece which are a preventing reason for many potential students in order to follow the HOU alternative for their studies. Such reasons was out of the scope of this project due to time limitations.

Another important potential future research could be to research ways that can be used in order to help the Greek universities to integrate in their curriculum the distance learning option, because nowadays, distance learning is offered only via the HOU. No Greek university offers such an option, so this could be a very important impediment for future students in a historical momentum where distance education worldwide is tending to increase in quantity and quality.

Finally, it is important to notice that as we saw in previous chapters this research had many restrictions, mainly due to time limitations. It is imperative that any future research will be held under different circumstances with less or no time limitations in order to help the future researcher to dig deeper into the problem. In such a way other factors described in the limitations part can be decisive too in order to accomplish a more detailed result, like the demographics of the respondents etc.

\subsection{Conclusions}

Distance education in Greece is not very popular. Although the last years it faced an enormous increase there are a lot issues that needed to be overcame in order to be able to say that it is a developed branch of contemporary education in Greece.

The results of this study were indicative in terms of the reasons which provide impediments to Greek students for choosing $\mathrm{HOU}$ instead of the traditional on campus one. Social circumstances like family, work and financial situation are the main reasons which make students pursue HOU educational system. Many factors from which the most important were family, friends and financial ones were the ones which affected the students' decision towards HOU.

Although the findings of this research were as expected, they are of the greatest importance as they are indicative of the socio- economic situation in contemporary Greece and because they can be the springboard for future research in the field in order to help the Greek educational system to move one step further.

The implications are vast also, as they have to do with strong societal influence which determine the contemporary Greek environment in great degree, in terms of providing education to people who need it in order to overcome the bad situation they are facing in their work, family or societal cycle.

Although this research did have some important restrains due to time and sample size limitations, it was quite impressive about its results, as it made more than clear what was obvious, that students in the contemporary Greek socio- economic environment in the middle of the vast financial crisis try to pursue their studies having in mind their number one paragon nowadays which is the economic one. So, it seems that HOU is a parallel way of studying in today's Greece which suits many Greeks due to circumstances.

\section{REFERENCES}

Bird, D.K. 2009, "The use of questionnaires for acquiring information on public perception of natural hazards and risk mitigation - a review of current knowledge and practice", Natural Hazards and Earth System Science, vol. 9, no. 4, pp. 1307-1325.

Bowen, G.A. 2008, "Naturalistic inquiry and the saturation concept: a research note", Qualitative Research, vol. 8, no. 1, pp. 137-152.

Collins, J. \& Pascarellat, E.T. 2003, "Learning on Campus and Learning at a Distance: A Randomized Instructional Experiment", Research in Higher Education, vol. 44, no. 3, pp. 315-326.

Denscombe, M. 2010, The good research guide: for small-scale social research projects, 4th edn, Open University Press, Maidenhead. 
Distancelearningschools.org, n.d. "Distance learning vs traditional campus college". [online]. Available at: < http://www.distancelearningschools.org/distance-learning-vs-traditional-campus-college/> [Accessed 12 November 2016].

E.K.E.P, n.d. Distance Learning. [online] Available at: < http://www.ekep.gr/english/education/exapostaseos.asp> [Accessed 11 November 2016].

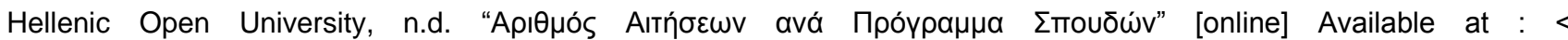
https://www.eap.gr/el/anakoinvseis-ekdilwseis/efimerida-ypiresias/statistika-stoixeia/933-

63dccfa0a536d7083dd66f37c386d14f> [Accessed 11 November 2016].

Gemmell, I., Harrison, R., Clegg, J. \& Reed, K. 2015, "Internationalisation in online distance learning postgraduate education: a case study on student views on learning alongside students from other countries", Innovations in Education and Teaching International, vol. 52, no. 2, pp. 137-147

Gravani M.; Hatzinikita V.; Zarifis G., "Factors Influencing Adult Distance Teaching and Learning Processes: The Case of the Open University". The International Journal of Learning. V 18 (5), 2012, pp. 307-319.

Guthrie, K.L. \& McCracken, H. 2010, "Making a difference online: Facilitating service-learning through distance education", The Internet and Higher Education, vol. 13, no. 3, pp. 153-157.

Malataras P; Palikarakis N., 2007. "Evaluation of an E-learning Course in Biomedical

Technology Management" [pdf]. Proceedings of the IEEE Symposium on Computer-Based Medical Systems. Available at: $<\quad$ https://www.researchgate.net/publication/4257826_Evaluation_of_an_Elearning_Course_in_Biomedical_Technology_Management> [Accessed 07 November 2016].

Muilenburg, L.Y. \& Berge, Z.L. 2005, "Student barriers to online learning: A factor analytic study", Distance Education, vol. 26, no. 1, pp. 29-48.

O'Reilly, M. \& Parker, N. 2013; 2012;, "'Unsatisfactory Saturation': a critical exploration of the notion of saturated sample sizes in qualitative research", Qualitative Research, vol. 13, no. 2, pp. 190-197.

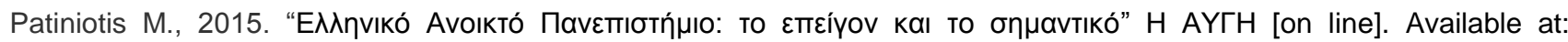
http://www.avgi.gr/article/10811/6083924/elleniko-anoikto-panepistemio-to-epeigon-kai-to-semantiko [Accessed 11 November 2016].

Prokou, E. 2014, "Adult Education/Lifelong Learning Policies in Greece in the Early 2010s", European Education, vol. 46, no. 1, pp. 34-54.

Perkowski, J. 2012, "The Role of Gender in Distance Learning: A Meta-Analytic Review of Gender Differences in Academic Performance and Self-Efficacy in Distance Learning", Journal of Educational Technology Systems, vol. 41, no. 3, pp. 267-278.

Queensland Health, 2007. "Queensland 'Stay On Your Feet" Community Good Practice Toolkit- Phase 1 materials: Surveys/questionnaires". [pdf]. Queensland Health. Available at: http://www.health.qld.gov.au/stayonyourfeet/documents/33345.pdf> [Accessed 20 November 2016].

Reese, S.A. 2015, "Online learning environments in higher education: Connectivism vs. dissociation", Education and Information Technologies, vol. 20, no. 3, pp. 579-588.

Sabine M; Amber S.; Rutherfoord B., 2012 "Interactive learning online: Challenges and opportunities" [pdf]. SIGITE '12 Proceedings of the 13th annual conference on Information technology education. Available at: http://sigite2012.sigite.org/wp-content/uploads/2012/08/panel4.pdf [Accessed 07 November 2016].

Siklaridi- Kolasa K., 2016. "Unemployment in Greece Remains More Than Double the Average Eurozone Rate". Greece.Greekreporter.com [online] Available at: < http://greece.greekreporter.com/2016/10/06/unemployment-in-greeceremains-more-than-double-the-average-eurozone-rate/> [Accessed 19 December 2016].

Smith, C.J. 2010, "'Distance learning' or 'learning at a distance'? Case study of an education initiative to deliver an inservice bachelor's degree in Zambia", Innovations in Education and Teaching International, vol. 47, no. 2, pp. $223-233$.

Statisticshowto.com, n.d., "Snowball Sampling: Definition, Advantages and Disadvantages" [online], Available at :< http://www.statisticshowto.com/snowball-sampling/> [Accessed 23 December 2016].

Sung, E. \& Mayer, R.E. 2012, "Five facets of social presence in online distance education", Computers in Human Behavior, vol. 28, no. 5, pp. 1738-1747.

Vergidis D., Panagiotakopoulos C., 2002. "Student Dropout at the Hellenic Open University: Evaluation of the graduate program, Studies in Education" The International Review of Research in Open and Distributed Learning [online]. Available at :< http://www.irrodl.org/index.php/irrodl/article/view/101/180> [Accessed 11 November 2016].

White S.; Gupta A.; Grudin J; Chesley H; Kimberly G; Sanocki E, 1999. "Evolving Use of A System for Education at a Distance" [pdf]. Available at: <http://research.microsoft.com/en-us/um/redmond/groups/coet/flatland/hicss/paperfinal.pdf> [Accessed 07 November 2016].

Yin, R.K. 2014. Case Study Research: Design and Methods. 5th Ed. Los Angeles: Sage Publication.

Young, J.R. 2000, Distance education seen as useful as classrooms, Chronicle of Higher Education, Washington.

$7482 \mid \mathrm{P}$ a g e

January, 2017

w w w. cirworld.com 


\section{APPENDIX 1: GLOSSARY OF TERMS AND ABBREVIATIONS}

$\boldsymbol{D S V} \quad$ : Department of Computers and Systems Sciences of Stockholm University Sweden

E.K.E.P : National Centre for Vocational Orientation

HOU : Hellenic Open University

\section{APPENDIX 2: INFORMED CONSENT FORM}

\section{Researcher:}

Karaoulanis Andreas

Tel: 0030123456789

E mail: researcher@gmail.com

Affiliation: Stockholm University/ DSV department

\section{Information about the research:}

\section{Aims:}

The aim of this research is to describe which factors affect the Greeks students' decision, to pursue their postgraduate degree via the Hellenic Open University online educational platform instead of the traditional one of the on campus education.

\section{Methods:}

This research will follow the case study strategy and questionnaires via email in terms of data collection.

\section{Anticipated outcomes:}

This research anticipate to describe via the factors influencing the students' decision possible social phenomena occurring in contemporary Greece.

Expectations about the participants' contribution:

- The participants are expected to answer some open ended questions via e- mails.

- The estimated time for answering them is no more than 10 minutes in total. No expenses needed.

- The participants will be given a free copy of the final report outcome.

\section{The right to withdraw consent:}

Participants are not obliged to continue in their role during this research if, at some subsequent stage, they no longer wish to. The consent form is not a contract that binds a person to the task of helping with the research. It is therefore very clear that participants have the right to withdraw their consent at any time.

\section{Confidentiality and security of data:}

- The researcher will treat the data provided by the participants under strict confidentiality and according to the Educational Researcher, Code of Ethics of the American Educational Research Association Approved by the AERA Council.

- The researcher will not mention any names in his research and all data acquired will be treated under strict anonymity.

- $\quad$ All email responses will be treated under strict confidentiality and it is the researcher's obligation to permanently delete them after the end of the research.

\section{Signature of the participant and date:}

I have read and understood the written details provided for me about the research and agree to participate in the project.

SIGNATURE

Signature of the researcher and date:

SIGNATURE

\section{APPENDIX 3: DATA COLLECTION PROTOCOL QUESTIONNAIRE}

No 1

Researcher's details: 
Name: Karaoulanis Andreas

E- mail: karaoulanisandreas@something.gr

Tel. number: 0030-123456

Affiliation: Stockholm University Sweden

The purpose of this questionnaire is to give answer to the question of why students in Greece choose to follow for their postgraduate studies the $\mathrm{HOU}$ (Hellenic Open University) instead of the on campus.

Please make sure if possible that you will return your answer as soon as possible in order to help the research progress.

Please return the questionnaire as soon as you will answer the questions provided in the following e- mail : karaoulanisandreas@something.gr.

Please answer to the following question by using the space provided in a concise and clear way.

1. Why you chose to follow distance learning courses? Give us 3 to 5 reasons. Write them with significance order from the more important to the less one.

2. Please write down in significance order the factors that you believe that affected your decision.

3. Please write down, according to your opinion, which are some pros and some cons of the distance learning educational method

4. Please write down, according to your opinion, which are some pros and some cons of the on campus educational method

5. Why did you choose distance learning only at postgraduate level and not for your bachelor's degree?

Thank you very much for your participation to this research.

APPENDIX 4: DEDOOSE SCREEN SHOTS 


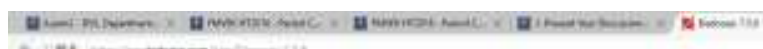

(3) dedocose
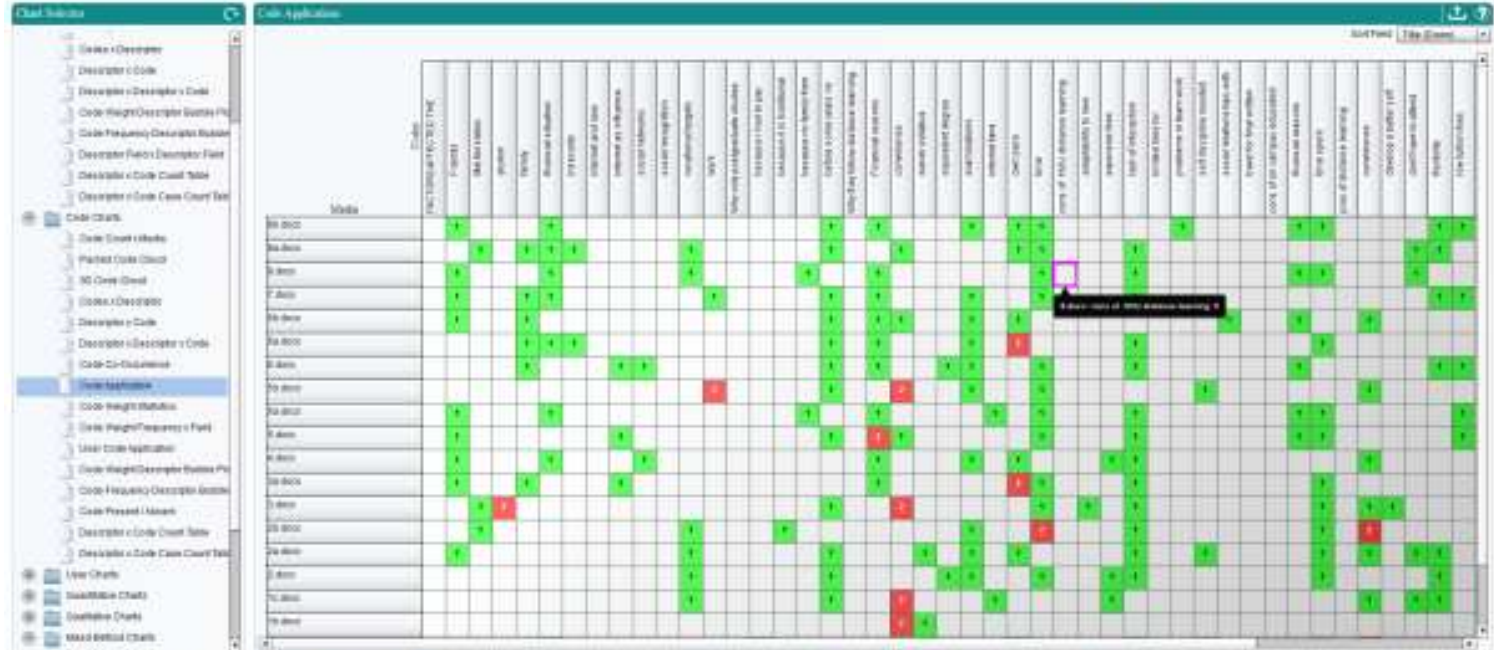

ap

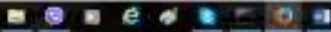
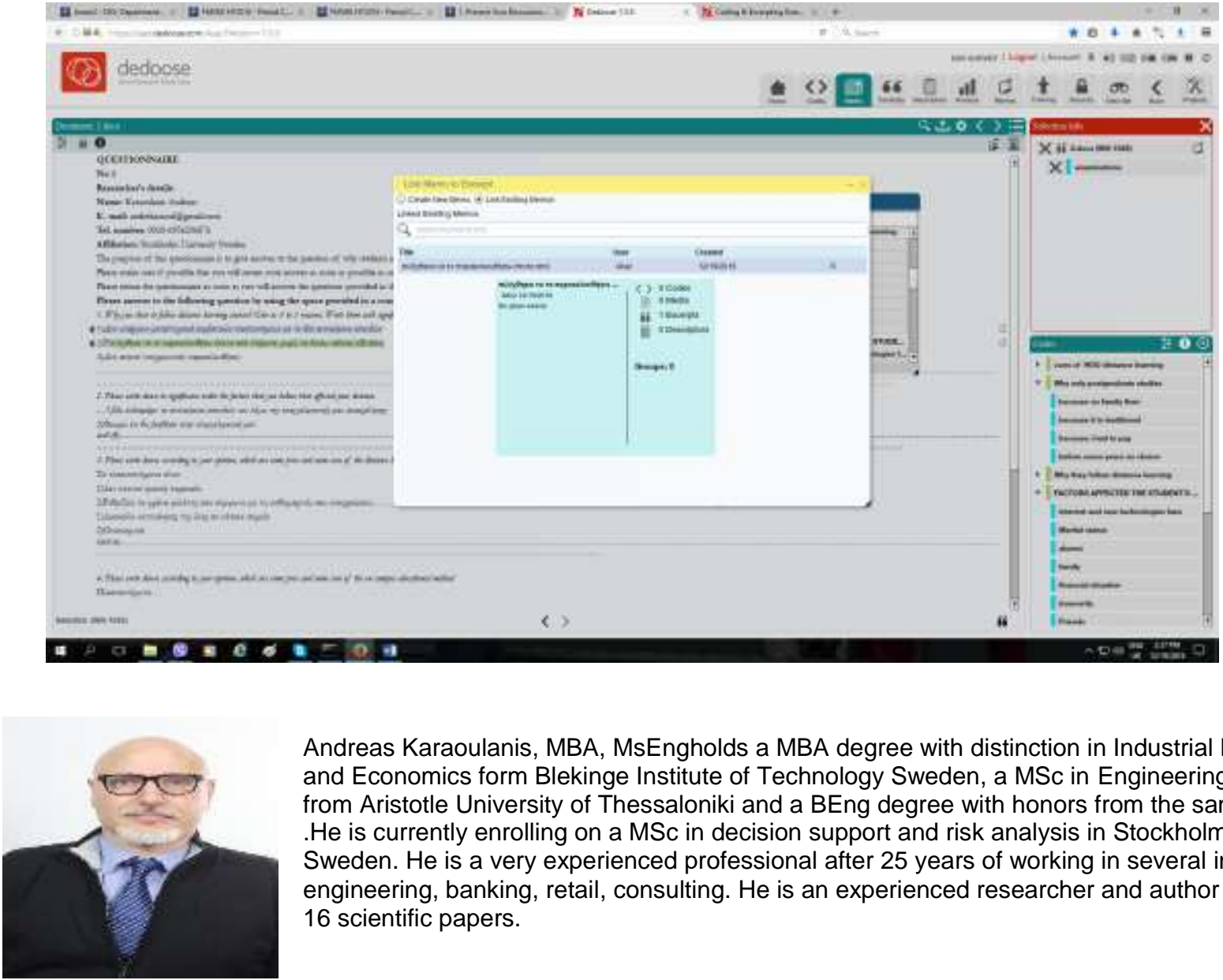

Andreas Karaoulanis, MBA, MsEngholds a MBA degree with distinction in Industrial Management and Economics form Blekinge Institute of Technology Sweden, a MSc in Engineering with honors from Aristotle University of Thessaloniki and a BEng degree with honors from the same University .He is currently enrolling on a MSc in decision support and risk analysis in Stockholm University Sweden. He is a very experienced professional after 25 years of working in several industries like engineering, banking, retail, consulting. He is an experienced researcher and author of more than 16 scientific papers. 